\title{
Characterization of Flavonoid Glycosides from Fenugreek (Trigonella foenum-graecum) Crude Seeds by HPLC-DAD-ESI/MS Analysis
}

\section{Zakia Benayad ${ }^{1, *}$, Carmen Gómez-Cordovés ${ }^{1}$ and Nour Eddine Es-Safi ${ }^{2, *}$}

1 Institute of Food science, Technology and Nutrition of the Spanish National Research Council (ICTAN-CSIC), Juan de la Cierva 3, Madrid 28006, Spain; E-Mail: cgcordoves@ifi.csic.es

2 Team of Organic Chemistry and Physico-Chemical Studies, Ecole Normale Superieure, Mohammed V University of Rabat, P.O. Box 5118, 10200 Rabat, Morocco

* Authors to whom correspondence should be addressed; E-Mails: zakia_ayad@hotmail.com (Z.B.); nouressafi@yahoo.fr (N.E.E.-S.); Tel.: +212-6-7264-3086 (N.E.E.-S.); Fax: +212-5-3775-9063 (N.E.E.-S.).

External Editor: Antonio Segura-Carretero

Received: 27 September 2014; in revised form: 28 October 2014 / Accepted: 3 November 2014 / Published: 11 November 2014

\begin{abstract}
Fenugreek (Trigonella foenum-graecum) is a medicinal plant which is widely used for its pharmacological properties. In this study the phenolic composition of fenugreek crude seeds originating from Morocco has been investigated. Extraction was performed from defatted seeds by a hydromethanolic solution using an Accelerated Solvent Extractor. HPLC technique coupled to negative ion electrospray ionization mass spectrometry and diode array detection was employed to identify the polyphenol in the obtained extract. The obtained results allowed the detection of 32 phenolic compounds among which various flavonoid glycosides and phenolic acids have been tentatively identified on the basis of their UV and MS spectra, and comparisons with standards when available, as well as with literature data. A systematic study of the obtained MS spectra and the observed fragmentation showed that most of the identified compounds were acylated and non-acylated flavonoids with apigenin, luteolin and kaempferol as aglycons. Hydroxycinnamic acids mostly dominated by caffeic acid derivatives were also detected. The quantitative analysis of the identified compounds showed that the phenolic composition of the studied crude fenugreek seeds was predominantly acylated and non-acylated flavone derivatives with apigenin as the main aglycon.
\end{abstract}


Keywords: Trigonella foenum-graecum; fenugreek seeds; Accelerated Solvent Extractor (ASE); flavonoids; flavones; flavonols; acylated glycosides; hydrocinnamic acids; mass spectrometry; LC-MS analysis

\section{Introduction}

Fenugreek (Trigonella foenum-graecum) is an annual plant of the Fabaceae family. The seeds of this plant are used by people in Asia, Africa and Mediterranean countries as one of the ingredients in daily diets [1]. It is used in many domains including medicine, nutrition, beverages, fragrances, cosmetics and for other industrial purposes [2]. Fenugreek is known to have several pharmacological effects including hypoglycaemia [3,4], hypocholesterolemia [5,6], gastroprotective [7], chemopreventive [8], antioxidant [9,10], antiinflammatory, antipyretic [11] and appetite stimulation [12].

Regarding its phytochemical composition, previously reported data on fenugreek highlighted the presence of alkaloids [13], flavonoids and phenolic acids [13-18], polysaccharides [13], triterpenoids [19], steroidal sapogenins [20-22] and nicotinic acid [23].

In Morocco, fenugreek has been widely used as a spice crop for a long time. It is also widely used in traditional medicine as a tonic, as a remedy against stomach disorders, diabetes, fever, anaemia, constipation, and as a galactogogue and for stimulation of appetite [24]. In an ongoing program aiming at the study of bioactive natural products, we investigated the chemical composition of crude fenugreek seeds. The beneficial health effects of this plant prompted us to explore its secondary metabolites in order to provide major information about its chemical content. The increasing interest of nutritional and pharmacological power of different parts of the plant motivated this investigation. The objectives of this research work were the extraction of phenolic compounds from crude fenugreek (Trigonella foenum-graecum) seeds by Accelerated Solvent Extractor (ASE) and the subsequent characterization of the flavonoid glycosides through HPLC/DAD/MS/ESI analysis. This was achieved through acquisition of the product ion mass spectra of deprotonated phenolic glycosides and to explore the observed fragmentations. The presence of many phenolic compounds pertaining to acylated and non-acylated flavonoids in addition to phenolic acids was observed. Their structures were elucidated based on the obtained UV and MS spectra. Quantitative analysis of the individual identified phenolic compounds is also reported. This work presents thus a more complete description of the phenolic compounds present in the crude fenugreek seeds.

\section{Results and Discussion}

The extracted crude fenugreek seeds sample was analyzed by HPLC coupled to both diode array and mass spectrometry detectors. The latter was used with an electrospray ionization source in negative ion mode. ESI LC-MS analysis was performed using cone voltage providing useful additional fragmentation data. A representative UV chromatogram is shown in Figure 1 indicating that the used HPLC conditions allowed a good separation of a large percentage of compounds. 
Figure 1. HPLC chromatogram of the studied fenugreek crude seeds recorded at $280 \mathrm{~nm}$.

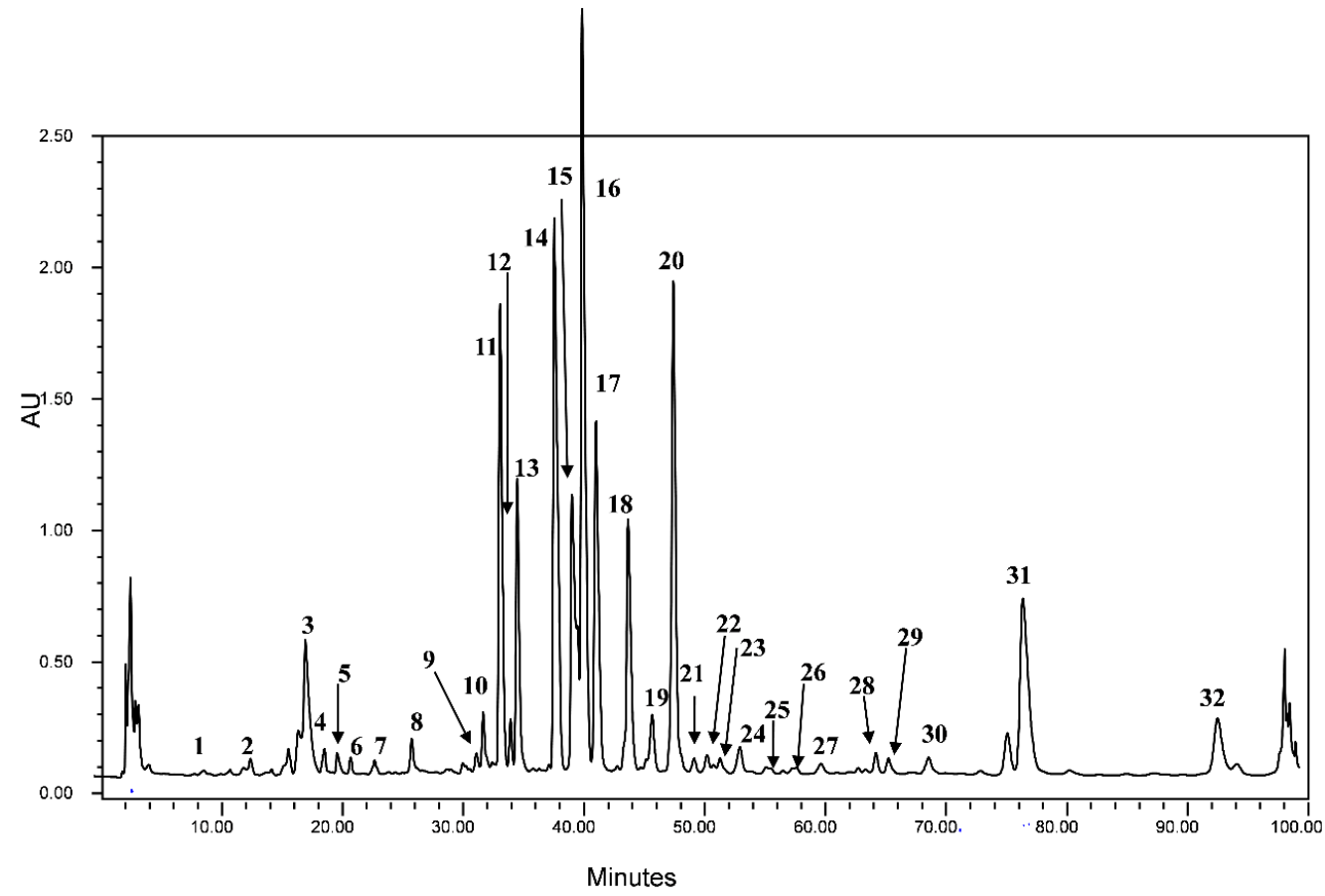

The HPLC separation profile revealed the presence of various chromatographic peaks in the studied sample extract. The structures of the separated compounds representing the major detected peaks and summarizing the obtained data for each of the detected chromatographic peak are discussed below. Compounds identification was based on the use of standard when available or on retention data, UV absorption, and ESI mass spectra and by comparison with literature data [25-38].

Online UV-visible spectra of the observed phenolic compounds were typical of flavone and flavonol glycosides in addition to phenolic acids. Most of the detected compounds showed UV absorptions maxima with two bands at 232-270 and 316-346 $\mathrm{nm}$ which are characteristic of flavonoids [39]. Some peaks with characteristic UV absorptions band for hydroxycinnamic acids were also detected.

The identification of the detected compounds was based on the search of the main molecular ions and also on some of the useful observed fragmentations. ESI LC-MS was performed using cone voltages with the higher cone voltage providing additional fragmentation data. Valuable information was also obtained concerning the presence and the nature of acyl groups. Compounds listed in Table 1 were restricted to those in which $[\mathrm{M}-\mathrm{H}]^{-}$ions were clearly detected. Among the observed peaks, some were too small to allow structural analyses.

Different compounds pertaining to flavonoids with $C$ - and/or $O$-hexosides and/or pentosides and with or without acyl groups have been detected. According to the obtained data, and taking into account the previously reported results on flavonoids mass spectrometry fragmentations, the position of glycosylation was in 7-hydroxyl group for flavones and flavonols and $6 \mathrm{C} / 8 \mathrm{C}$ position for $C$-glycosides [32,40-42]. Moreover, the determination of linkage type of the $O$ - and/or $C$-glycosides and differentiation of the positional flavones and flavonols glycoside isomers was determined through comparison of the relative intensity of the product ions spectra [34,43-45]. On the other hand, the interglycosidic linkage involved between the sugar moieties in the $O$ - and/or $C$-glycosyl flavones and flavonols was in $1 \rightarrow 2$ and $1 \rightarrow 6$ linkages [45,46]. 
Table 1. Chromatographic, spectral data and identification of non-acylated flavonoid glycosides in fenugreek crude seeds.

\begin{tabular}{cccccc}
\hline Peak & $\boldsymbol{R}_{\mathbf{t}}(\mathbf{m i n})$ & $\lambda_{\max }(\mathbf{n m})$ & {$[\mathbf{M}-\mathbf{H}]^{-}$} & Fragment Signals $(\boldsymbol{m} / \mathbf{z})$ & Compound Identification \\
\hline 9 & 31.74 & $234,272,334$ & 593 & $473,383,353$ & apigenin 6,8-di $C$-hexoside (vicenin 2 isomer) \\
11 & 33.65 & $232,272,334$ & 593 & $473,383,353$ & apigenin 6,8-di $C$-glucoside (vicenin 2) \\
13 & 35.06 & $232,270,336$ & 593 & $473,383,353$ & apigenin 6,8-di $C$-hexoside (vicenin 2 isomer) \\
14 & 38.12 & $232,270,336$ & 563 & $443,383,353$ & apigenin 8- $C$-xyloside-6- $C$-glucoside (vicenin 3) \\
17 & 41.53 & $230,270,336$ & 563 & $443,383,353$ & apigenin 6- $C$-xyloside-8- $C$-glucoside (vicenin 1$)$ \\
19 & 46.17 & $232,272,338$ & 577 & $503,473,383,353$ & apigenin 8- $C$-rhamnoside-6- $C$-glucoside \\
31 & 77.08 & $232,270,316$ & 593 & $447,429,309,285$ & kaempferol 7- $O$-rhamnosyl-(1 $\rightarrow 2$ )-glucoside \\
\hline
\end{tabular}

Scheme 1. Ion nomenclature used for flavonoid glycosides (illustrated on kaempferol 7-O-rhamnosyl-(1 $\rightarrow 2)$-glucoside $(\mathbf{A})$ and a $C$-hexoside derivative (B)).

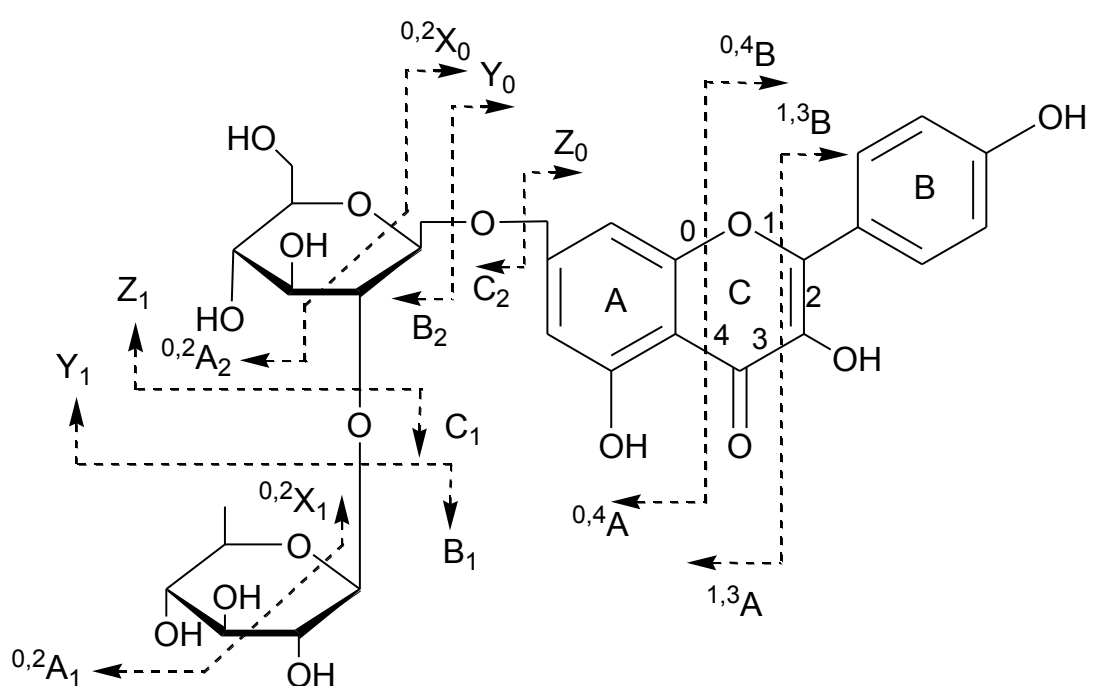

(A)

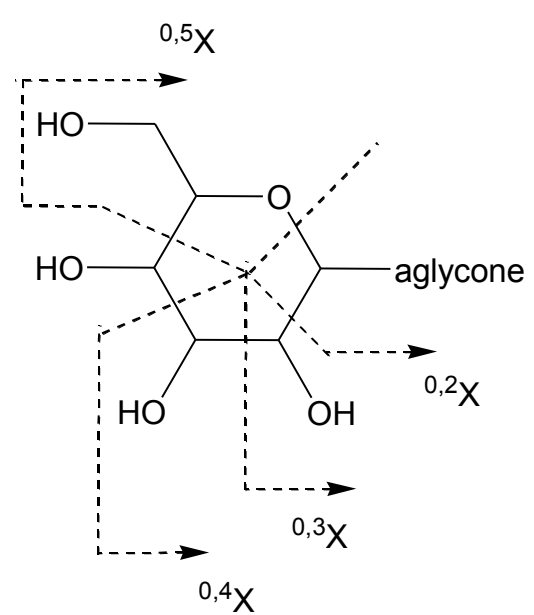

(B) 
In flavonoids mass spectrometry, the major diagnostic fragmentations for flavonoid identification are those involving the cleavage of two $\mathrm{C}-\mathrm{C}$ bonds of the $\mathrm{C}$-ring giving two structurally informative fragment ions. These ions provide information on the number and type of substituents in A- and B-rings. In this paper, these fragment ions are designated according to the nomenclature previously proposed [47]. For free aglycone, the ${ }^{\mathrm{i}, \mathrm{j}} \mathrm{A}$ and ${ }^{\mathrm{i}, \mathrm{j}} \mathrm{B}$ labels refer to the fragments containing intact A- and B-rings, respectively, in which the superscripts $i$ and $j$ indicate the $\mathrm{C}$-ring bonds that have been broken. For flavonoid glycosides, the classical nomenclature proposed by Domon and Costello for glycoconjugates was adopted to designate the fragmentations [33]: ${ }^{k}{ }^{\mathrm{X}} \mathrm{X}_{j}, \mathrm{Y}^{n}{ }_{j}, \mathrm{Z}^{n}{ }_{j}$ represents the ions still containing the aglycone, where $j$ is the number of the interglycosidic bonds broken (counted from the aglycon) and $k$ and $l$ denote the cleavage within the carbohydrate rings, $n$ represents the position where the oligosaccharide is attached to the aglycone (Scheme 1).

The detected flavonoids were divided into non acylated and acylated glycosides. The first group consisted of flavone di- $C$-glycosides and flavonol $O$-diglycosides, which were characterized by mass losses corresponding to the fragmentations ${ }^{0,2} \mathrm{X}_{0},{ }^{0,3} \mathrm{X}_{0},{ }^{0,1} \mathrm{X}_{0},{ }^{1,5} \mathrm{X}_{0}$ and $-\mathrm{Y}_{\mathrm{j}} \mathrm{Y}_{0}{ }^{7}$ of the sugar moieties. The second group consisted of flavone $O, C$-glycosides with an acyl moiety on the $C$-glycosyl due to the presence of losses corresponding to the fragmentations $-\mathrm{Z}_{\mathrm{j}}^{-}$(acyl - 18), ${ }^{0,2} \mathrm{X}_{0},{ }^{0,3} \mathrm{X}_{0}[35,36,45]$. The acyl groups were dihydroferulic, hydroxyferulic, gallic, dihydrogallic, methoxygallic, quinic, malonyl and acetyl moieties with a predominance of the dihydrogallic acid.

\subsection{Non-Acylated Flavone and Flavonol Glycosides}

Compounds 9, 11 and 13 present the same molecular ion at $m / z: 593[\mathrm{M}-\mathrm{H}]^{-}$which was observed as base peak (Table 1). The MS data showed fragment ions at $m / z: 383(\mathrm{Ag}+113)$ and $m / z: 353(\mathrm{Ag}+83)$ which are characteristics of di $C$-glycosylflavone fragmentations [48]. Another fragment ion signal was observed at $m / z: 473[(\mathrm{M}-\mathrm{H})-120]^{-}$and corresponding to the ${ }^{0,2 "} \mathrm{X}_{0}$. This signal was observed with a low relative intensity, indicating to the loss of another glycosyl residue [29,30]. A comparison of the relative intensity of the observed fragment signals showed that the signal located at $\mathrm{m} / \mathrm{z} 383$ was higher than that at $\mathrm{m} / z 473$ suggesting an apigenin aglycone. Consequently these compounds were concluded to be apigenin 6,8-di $C$-hexoside isomers as observed in our previous spectral analysis of compounds from fenugreek germinated seeds [32]. Compound 11 presents fragmentations similar to those indicated for apigenin 6,8-di $C$-glucoside [16,49]. The structure of vicenin-2 was then proposed for this compound.

Compounds 14 and 17 present a molecular ion signal at $m / z: 563[\mathrm{M}-\mathrm{H}]^{-}$(base peak). Additional

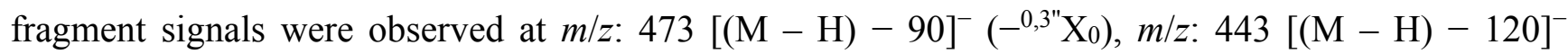
$\left(-^{0.2^{\prime \prime}} \mathrm{X}_{0}\right), m / z: 383[(\mathrm{M}-\mathrm{H})-120-60]^{-}\left(-^{0,3{ }^{\prime \prime}} \mathrm{X}_{0}\right)$ and $m / z: 353[(\mathrm{M}-\mathrm{H})-120-90]^{-}\left(-^{0,2^{\prime \prime \prime}} \mathrm{X}_{0}\right)$. These neutral losses are characteristics of a glucosyl and pentosyl residues as previously reported $[32,35,45]$. The fragments ion signals observed at $m / z: 383(\mathrm{Ag}+113)$ and $m / z: 353(\mathrm{Ag}+83)$ are typical of di $C$-glycosylflavones as mentioned above. These results suggested thus that compounds $\mathbf{1 4}$ and $\mathbf{1 7}$ were isomers with skeletons consisting of apigenin with a pentosyl and a glucosyl linked to the 6 and 8 positions.

Taking into account the previously reported data concerning the potential of MS methods in the determination of the type of the substitution of a sugar at the 6 and 8 positions of a 6,8-di $C$-glycosylflavones where the preferential fragmentation of the sugar moiety at the 6 position 
has been shown and with regard to the obtained results, compound 17 was proposed to be apigenin 6-C-xyloside-8-C-glucoside (vicenin 1), while compound $\mathbf{1 4}$ was proposed to be apigenin 8-C-xyloside-6- $C$-glucoside (vicenin 3). This is in agreement with the results previously reported on fenugreek seeds $[14,16,32]$.

Compound 19 presents a molecular ion signal at $m / z$ : $577[\mathrm{M}-\mathrm{H}]^{-}$. The observed fragmentation pattern was typical of a di $C$-glycosylflavone [48]. The MS data showed fragment ion signals at

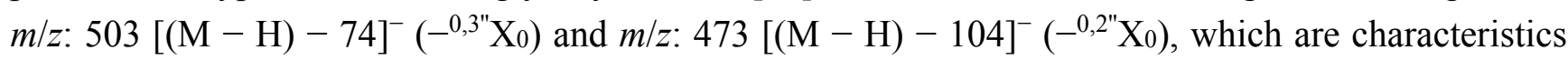
of a $C$-linked rhamonsyl $[35,37]$. Other fragments signals at $m / z: 383[(\mathrm{M}-\mathrm{H})-90]^{-}\left(-^{0,3{ }^{\prime \prime \prime}} \mathrm{X}_{0}\right)$ and $m / z: 353[(\mathrm{M}-\mathrm{H})-120]^{-}\left(-^{0,2^{\prime \prime}} \mathrm{X}_{0}\right)$ were also observed and corresponded to the loss of a $C$-glucosyl moiety [36,45]. The observed relative intensity of the fragment ion signals released from the $C$-glucosyl moiety were higher than those of the $C$-rhamonsyl one in agreement with the glucosyl moiety fixed at the 6 position while the the rhamnosyl group was linked at the 8 position [42]. Therefore compound 19 was concluded to be apigenin 8- $C$-rhamnosyl 6- $C$-glucoside.

Compound 31 presents a molecular ion at $m / z: 593[\mathrm{M}-\mathrm{H}]^{-}$. The obtained MS data also showed fragment ion signals at $m / z: 447[(\mathrm{M}-\mathrm{H})-146]^{-}\left(-\mathrm{Y}_{1^{\prime \prime}}{ }^{7}\right), m / z: 327[(\mathrm{M}-\mathrm{H})-146-120]^{-}\left(-^{0,2^{\prime \prime}} \mathrm{X}_{0}\right)$ and $m / z: 285[(\mathrm{M}-\mathrm{H})-146-162]^{-}\left(-\mathrm{Y}_{0}{ }^{7}\right)$. The latter signal corresponding to the aglycon moiety indicated a loss of the $O$-rhamanosyglucosyl in agreement with previously reported data [31]. According to Cuyckens et al. (2000) [46], the presence of the ion $\left(-0,2^{\prime \prime} \mathrm{X}_{0}\right)$ with a high abundance is characteristic of the $1 \rightarrow 2$ isomer. Therefore, this compound could be kaempferol 7-O-(2"rhamnosyl)-glucoside.

\subsection{Acylated Flavone and Flavonol Glycosides}

Compound 10 presents a molecular ion at $m / z: 771[\mathrm{M}-\mathrm{H}]^{-}$(Table 2). The MS data showed fragment signals at $m / z: 383(\mathrm{Ag}+113)\left(-^{0,3 " ' \mathrm{X}}\right)$ and $m / z: 353(\mathrm{Ag}+83)\left(-^{0,2 " ' \mathrm{X}}\right)$ in agreement with a di $C$-glycosylflavone [48]. Additional fragment signals were observed at $m / z: 593[\mathrm{M}-\mathrm{H}-178]^{-}$ $\left(\mathrm{Y}^{2 "}\right)($ acyl -18$)$ and $m / z: 473[(\mathrm{M}-\mathrm{H})-178-120]^{-}\left(-^{0.2^{\prime \prime}} \mathrm{X}_{0}\right)$ suggesting an $O$-(Acyl)-glycosylflavone. The observed loss of $178 \mathrm{amu}$ is in agreement with the molecular mass of a dehydrated dihydroferulic acid moiety connected through an interglycosidic $1 \rightarrow 2$ linkage to the $C$-glucosyl unit. This is due to the high relative intensity of the signal observed at $m / z$ : 593 which was observed as base peak $[43,45]$. From these results, compound $\mathbf{1 0}$ was tentatively concluded to be apigenin 6-C-glucosyl 8-C-(2"-Odihydroferuloyl)-glucoside.

The compound 12 showed a mass molecular ion at $m / z: 749[\mathrm{M}-\mathrm{H}]^{-}$. The MS data also showed a fragment signal at $m / z: 593[\mathrm{M}-\mathrm{H}-156]^{-}$corresponding to the loss of a rhamnosyl moiety. Further ion signals were observed at $m / z: 503[(\mathrm{M}-\mathrm{H})-156-90]^{-}\left({ }^{0,3} \mathrm{X}_{0}{ }^{-}\right), 473[(\mathrm{M}-\mathrm{H})-156-120]^{-}$ $\left({ }^{0,2} \mathrm{X}_{0}{ }^{-}\right)$, with a low relative intensity, indicating the loss of a glucose residue. In the same spectrum a fragment ions signals were observed at $m / z: 383[(\mathrm{M}-\mathrm{H})-156-120-90]^{-}$and $353[(\mathrm{M}-\mathrm{H})-156$ $-120-120]^{-}$, with high relative intensities, indicating to the loss of another glucose residue. Moreover, the ion fragment signals observed at $\mathrm{m} / \mathrm{z}: 383$ (aglycone +113 ) and $\mathrm{m} / \mathrm{z}: 353$ (aglycone + 83), are characteristic of a di $C$-glycosylflavone fragmentation [48] with apigenin as aglycone. The fragmentations observed after the 156 amu neutral loss were similar to that of vicenin. Consequently compound $\mathbf{1 2}$ was concluded to be an acylated vicenin derivative. 
Table 2. Chromatographic, spectral data and identification of acylated flavonoid glycosides in fenugreek crude seeds.

\begin{tabular}{|c|c|c|c|c|c|}
\hline Peak & $R_{\mathrm{t}}(\min )$ & $\lambda_{\max }(\mathrm{nm})$ & {$[\mathbf{M}-\mathbf{H}]^{-}$} & Fragment Signals $(m / z)$ & Compound Identification \\
\hline 10 & 32.28 & 234,334 & 771 & $593,503,473,383,353$ & apigenin 6-C-glucosyl 8-C-(2"-O-dihydroferuloyl)-glucoside \\
\hline 12 & 34.51 & $232,270,336$ & 749 & $593,503,473,383,353$ & vicenin derivative \\
\hline 15 & 39.58 & $234,270,348$ & 895 & $563,447,357,327,284$ & luteolin 7-O-[6"-dihydrogalloyl]-glucosyl-8-C-pentosyl-( $1 \rightarrow 6)$-glucoside \\
\hline 16 & 40.40 & 270,346 & 895 & $563,447,357,339,327,285$ & luteolin 7-O-[6"-dihydrogalloyl]-glucosyl-8-C-pentosyl-( $(1 \rightarrow 2)$-glucoside \\
\hline 18 & 44.22 & $232,268,336$ & 863 & $563,443,323,311$ & apigenin 7-O-(2"-dihydrogalloyl)-rhamonsyl-6-C-(2"'-pentosy)-glucoside \\
\hline 20 & 47.94 & $234,270,336$ & 863 & $563,443,323,311,283$ & apigenin 7-O-(2"-dihydrogalloyl)-rhamonsyl-6-C-(2"'-pentosy)-glucoside \\
\hline 21 & 49.62 & $232,270,336$ & 725 & $533,443,413,383,353$ & apigenin 6-C-pentosyl 8-C-(2"-O-hydroxyferuloyl)-pentoside \\
\hline 22 & 50.69 & $232,272,340$ & 759 & $593,473,383,353$ & apigenin 6-C-glucosyl 8-C-(6"-O-methoxygalloyl)-glucoside \\
\hline 23 & 51.74 & $234,270,336$ & 863 & $563,431,323,283$ & apigenin and 7-O-(6"-dihydrogalloyl)-rhamonsyl-6-C-(2"'-pentosy)-glucoside \\
\hline 24 & 53.33 & 232,316 & 877 & $563,473,447,327,285$ & kaempferol 7-O-(6"-galloyl)-glucosyl 6-C-(2"'pentosyl)-rhamnoside \\
\hline 25 & 55.50 & $232,270,346$ & 877 & $533,447,357,339,305,285$ & luteolin 7-O-(2"-galloyl)-glucosyl 6-C-(2"'pentosyl)-rhamnoside \\
\hline 26 & 58.02 & $232,270,338$ & 893 & $577,473,383,353$ & apigenin 7-O-(6"-dihydrogalloyl)-glucosyl-8- $C$-rhamnosyl-6- $C$-glucoside \\
\hline 27 & 60.02 & $230,270,338$ & 893 & $577,473,383,353$ & apigenin 7-O-(2"-dihydrogalloyl)-glucosyl-8- $C$-rhamnosyl-6- $C$-glucoside \\
\hline 28 & 64.59 & $232,270,344$ & 925 & $605,563,443,383,353$ & luteolin 7-O-(6"-quinoyl)-rhamnosyl-6- $C$-pentosyl-8- $C, O-(6$ "'acetyl)-glucoside \\
\hline 29 & 65.60 & $232,270,344$ & 547 & $487,457,383,353,283$ & luteolin 8-C-(2"-malonyl)-glucoside \\
\hline 30 & 68.87 & 270,344 & 935 & $651,547,461,327,285$ & $\begin{array}{l}\text { luteolin 7-O-(2"dihydrogalloyl)-pentosyl-4'- } \\
O-(2 " ', 6 \text { "'-malonyl-pentosyl)-rhamnoside }\end{array}$ \\
\hline 32 & 93.20 & $232,270,318$ & 1133 & $1063,917,577,164,293$ & $\begin{array}{c}\text { kaempferol 7-O-(2"',6"',2"-malonyl)-rhamonsyl-diglucosyl-3- } \\
O-(6 " '+1 \text { rhamnosyl)-rhamnoside }\end{array}$ \\
\hline
\end{tabular}


Compound 21 presents a molecular ion at $m / z: 725[\mathrm{M}-\mathrm{H}]^{-}$. The characteristic fragment signals at $m / z: 383(\mathrm{Ag}+113)$ and $m / z: 353(\mathrm{Ag}+83)\left(-{ }^{0,3}{ }^{\prime \prime} \mathrm{X}_{0}\right)$, indicating a di $C$-glycosylflavone linkage were observed [48]. The fragment signals observed at $m / z: 533[(\mathrm{M}-\mathrm{H})-192]^{-}($acyl -18$), m / z: 443$ $[(\mathrm{M}-\mathrm{H})-192-90]^{-}\left({ }^{0.2 "} \mathrm{X}_{0}\right)$ and $m / z: 413[(\mathrm{M}-\mathrm{H})-192-120]^{-}\left(-^{0,1 "} \mathrm{X}_{0}\right)$, corresponding to the loss of the an $O$-(acyl)- $C$-pentosyl with a $1 \rightarrow 2$ interglycosidic linkage due to the high relative intensity (70\%) of the signal observed at $\mathrm{m} / \mathrm{z}: 533$ [50]. The observed neutral loss of a $192 \mathrm{amu}$ corresponded to a dehydrated hydroxyferulic acid moiety. On the basis of these results and on the fact that the relative intensity of the ion signal at $m / z: 353\left(-^{0,3 " '} \mathrm{X}_{0}\right)$ was higher than that observed at $m / z: 413\left(-^{0,1 "} \mathrm{X}_{0}\right)$, compound 21 was proposed to be apigenin 6-C-pentosyl 8-C-(2"- $O$-hydroxyferuloyl)-pentoside.

Compound 22 presents a molecular ion at $m / z: 759[\mathrm{M}-\mathrm{H}]^{-}$. The MS data showed fragments signals at $m / z: 593[(\mathrm{M}-\mathrm{H})-166]^{-}($acyl -18$)$ indicating a loss of an $O$-acyl moiety. The latter was concluded to be linked through a $C$-glycosylation, due to the presence of the fragments ions $\mathrm{m} / \mathrm{z}$ : $383(\mathrm{Ag}+113)$ and $m / z: 353(\mathrm{Ag}+83)$ which is indicative of di $C$-glycosylflavone [50]. Other fragment signals were observed at $m / z: 473[(\mathrm{M}-\mathrm{H})-120]^{-}\left(-^{0,2^{\prime \prime}} \mathrm{X}_{0}\right), m / z: 383[(\mathrm{M}-\mathrm{H})-120-90]$ $\left(-^{0,3^{\prime \prime \prime}} \mathrm{X}_{0}\right)$ and $m / z: 353[(\mathrm{M}-\mathrm{H})-120-120]^{-}\left(-^{0,2^{2 \prime \prime}} \mathrm{X}_{0}\right)$ (base peak), corresponding to the loss of the diglucosyl residue [35]. On the basis of these results and on the fact that the fragment signal observed at $m / z: 593[(\mathrm{M}-\mathrm{H})-166]^{-}($acyl -18$)$, showed a very low relative intensity $(10 \%)$, compound 22 was concluded to be apigenin 6-C-glucosyl 8-C-(6"-O-methoxygalloyl)-glucoside.

Compounds 15 and 16 present a molecular ion at $m / z$ : $895[\mathrm{M}-\mathrm{H}]^{-}$. The MS data showed fragment signals at $m / z: 563[(\mathrm{M}-\mathrm{H})-(\text { acyl }-2 \mathrm{H})-162]^{-}$, indicating an $O$-acylglycosylation on a phenolic hydroxyl through $1 \rightarrow 6$ interglycosidic linkage, due to their low relative intensity. Other fragment signals were observed at $m / z: 447[(\mathrm{M}-\mathrm{H})-(\mathrm{acyl}+2 \mathrm{H})-162-(132-16)]^{-}, \mathrm{m} / z: 357[(\mathrm{M}-\mathrm{H})-$ $($ acyl $+2 \mathrm{H})-162-(132-16)-90]^{-}\left(-^{\left.0,3 " ' \mathrm{X}_{0}\right)}(\mathrm{Ag}+71)\right.$ and $m / z: 327[(\mathrm{M}-\mathrm{H})-(\mathrm{acyl}+2 \mathrm{H})+$ $162-(132-16)-120]^{-}\left(-^{0,2^{\prime \prime}} \mathrm{X}_{0}\right)(\mathrm{Ag}+41)$, corresponding to the loss of a pentosylglucoside with an interglycosidic $1 \rightarrow 6$ linkage in compound 15 , and $1 \rightarrow 2$ for compound $\mathbf{1 6}$, due to a high relative intensity of the fragment ion $m / z$ : 447 (compound 16) than in compound 15. The last fragment signals observed at $m / z: 357(\mathrm{Ag}+71)$ and $m / z: 327(\mathrm{Ag}+41)$ are typical of mono-glycosylflavones [31,48]. The higher intensity of the signal $(\mathrm{Ag}+41)$ which was observed as base peak confirmed the 8-C substitution [26]. Therefore luteolin 7-O-[6"-dihydrogalloyl]-glucosyl-8- $C$-pentosyl- $(1 \rightarrow 6)$-glucoside was attributed to compound 15 and luteolin 7-O-[6"-dihydrogalloyl]-glucosyl-8- $C$-pentosyl- $(1 \rightarrow 2)$-glucoside was attributed to compound 16.

Compounds 18, 20 and 23 present a molecular ion at $m / z: 863[\mathrm{M}-\mathrm{H}]^{-}$. The MS data showed a fragment signal at $m / z: 563[(\mathrm{M}-\mathrm{H})-(\text { acyl }-18)-146]^{-}\left(\mathrm{Y}_{0}{ }^{7-}\right)$, corresponding to the loss of an $O$-acylated rhamnosyl moiety. Other fragment signals were observed at $m / z: 437[(\mathrm{M}-\mathrm{H})-300-90]^{-}$ $\left(-^{0,2^{\prime \prime \prime}} \mathrm{X}_{0}\right), m / z: 443[(\mathrm{M}-\mathrm{H})-300-120]^{-}\left(\left(^{0,1^{\prime \prime \prime}} \mathrm{X}_{0}\right), m / z: 353[(\mathrm{M}-\mathrm{H})-210]^{-}\left(-^{0,3^{\prime \prime \prime}} \mathrm{X}_{0}\right)\right.$, $m / z: 323[(\mathrm{M}-\mathrm{H})-300-240]^{-}\left(-^{0,1^{\prime \prime \prime}} \mathrm{X}_{0}{ }^{0.2{ }^{2 \prime \prime}} \mathrm{X}_{0}\right)$ and $m / z: 311[(\mathrm{M}-\mathrm{H})-300-240-41]^{-}(\mathrm{Ag}+41)$. These fragmentations are in agreement with the presence of a disaccharide moiety consisting of a pentosyl and a glucosyl residues. These were concluded to be linked through an interglycosidic linkage, due to the presence of the signal at $m / z: 311(\mathrm{Ag}+41)$, which is typical of the mono $C$-glycosylflavones [26,48]. This was also confirmed through the neutral loss of a $240(120+120)$ amu confirming this hypothesis. The interglycosidic linkage of the pentosyl glucosyl was at 2"' position with a $6 C$-glycosylation in compounds $\mathbf{1 8}$ and 23. Compound $\mathbf{2 0}$ presents the same 
fragments as compounds 18 and 23 with the fragment signal at $m / z: 283(\mathrm{Ag}+13)$ as base peak. Consequently apigenin 7-O-(2"-dihydrogalloyl)-rhamonsyl-6-C-(2"'-pentosy)-glucoside were proposed for compounds 18 and 20 and apigenin and 7-O-(6"-dihydrogalloyl)-rhamonsyl-6- $C$-(2"'-pentosy)-glucoside was proposed for compound 23.

Compound 24 and 25 present a molecular ion at $m / z: 877[\mathrm{M}-\mathrm{H}]^{-}$. The MS data showed fragment ions at $m / z: 563[(\mathrm{M}-\mathrm{H})-(\operatorname{acyl}-18)-162]^{-}\left(\mathrm{Y}_{0}{ }^{7-}\right)$, with a very low relative intensity $(7 \%)$, indicating an $O$-(acyl)-glycosylation on the phenolic hydroxyl by interglycosidic $1 \rightarrow 6(\mathbf{2 4})$ and $1 \rightarrow 2$ linkage (25). Other fragment signals were observed at $m / z: 473[(\mathrm{M}-\mathrm{H})-162-(\text { acyl }-18)-90]^{-}$

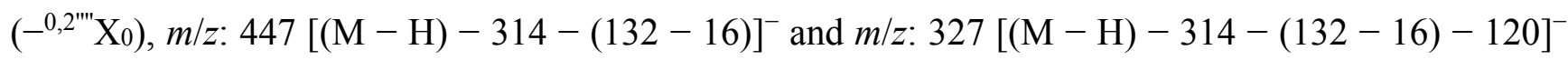
$\left(-^{1.5^{\prime \prime \prime}} \mathrm{X}_{0}\right)$. The latter's $\left(-^{0,2^{\prime \prime \prime}} \mathrm{X}_{0}\right)$ and $\left(-^{1,5^{\prime \prime \prime}} \mathrm{X}_{0}\right)$ corresponding to the loss of the pentosyl-rhamnoside residue by interglycosidic linkage at 2"' and 6"' position [35]. The presence of the fragment ion $m / z$ : $327(\mathrm{Ag}+41)$, is characteristic of the mono-luteolin $C$-glycosyl derivative [48]. In compound 25, the presence of the fragment ions at $m / z: 357(\mathrm{Ag}+71), m / z: 339(\mathrm{Ag}+71-18)$ and $m / z: 305(\mathrm{Ag}+19)$ (base peak), more abundant in the $6-C$ than in $8-C$ isomers were observed $[31,48]$. These results, suggested that compounds 24 and 25 could be kaempferol 7-O-(6"-galloyl)-glucosyl 6-C-(2'"pentosyl)-rhamnoside (24) and luteolin 7-O-(2"-galloyl)-glucosyl 6-C-(2"'-pentosyl)-rhamnoside (25).

Compounds 26 and 27 present a molecular ion at $m / z: 893[\mathrm{M}-\mathrm{H}]^{-}$. The MS data also showed fragment signals at $m / z: 577[(\mathrm{M}-\mathrm{H})-(\operatorname{acyl}-18)-162]^{-}\left(-\mathrm{Y}_{0}{ }^{7}\right)$ in agreement with the loss of an $O$-(acyl)-glucosyl $(154+162 \mathrm{amu})$ moiety. This residue was concluded to be linked to the phenolic hydroxyl by interglycosidic $1 \rightarrow 2$ linkage (27), due to the high relative intensity of the signal located at $m / z: 577$ [51]. Other fragment signals were observed at $m / z: 473[(\mathrm{M}-\mathrm{H})-316-104]^{-}\left(-{ }^{0,2^{\prime \prime \prime}} \mathrm{X}_{0}\right)$, $m / z: 383[(\mathrm{M}-\mathrm{H})-316-104-90]^{-}\left(-^{\left.0,3^{\prime \prime \prime} \mathrm{X}\right)}\right.$ and $m / z: 353[(\mathrm{M}-\mathrm{H})-316-104-120]^{-}\left(-^{0,2^{\prime \prime \prime}} \mathrm{X}_{0}\right)$ corresponding to the loss of the rhamonsyl $\left(-^{\left.0,2 ' \mathrm{X}_{0}\right)}\right.$ and glucosyl $\left(-^{0,22^{\prime \prime \prime}} \mathrm{X}_{0}\right)$ residues. The fragment signals at $m / z: 383(\mathrm{Ag}+113)$ and $m / z: 353(\mathrm{Ag}+83)$ which are characteristics of di $C$-glycosilflavone were also observed. The signal located at $m / z: 353$ was observed with a higher intensity in agreement with a 6-C-glucosyl-8- $C$-rhamnosyl-substitution. On the basis of the obtained results, these compounds were concluded to be apigenin 7-O-(6"-dihydrogalloyl)-glucosyl-8- $C$-rhamnosyl-6- $C$-glucoside (26) and apigenin 7-O-(2"-dihydrogalloyl)-glucosyl-8- $C$-rhamnosyl-6- $C$-glucoside (27).

Compound 28 presents a molecular ion at $m / z$ : $925[\mathrm{M}-\mathrm{H}]^{-}$. The MS showed fragment signals at $m / z: 605[(\mathrm{M}-\mathrm{H})-(\operatorname{acyl}-18)-146]^{-}\left(-\mathrm{Y}_{0}{ }^{7}\right)$, with a low relative intensity $(6 \%)$, corresponding to the loss an $O$-(acyl)-rhamonsyl $(174+146 \mathrm{amu})$ with a $1 \rightarrow 6$ interglycosidic linkage [51]. Other fragment signals were observed at $m / z: 563[(\mathrm{M}-\mathrm{H})-320-(\operatorname{acyl}-18)]^{-}, m / z: 443[(\mathrm{M}-\mathrm{H})-320-$ $($ acyl -18$)-120]^{-}\left(-^{0,2^{\prime \prime \prime}} \mathrm{X}_{0}\right)$, indicating to the $\mathrm{Z}_{\mathrm{j}}^{-}($acyl -18$)$ loss connected by interglycosidic linkage on the sugar moiety with a $C$-glycosylation. The ion $m / z: 383[(\mathrm{M}-\mathrm{H})-320-(\operatorname{acyl}-18)-120-60]^{-}$ $\left(-^{0,3^{\prime \prime \prime}} \mathrm{X}_{0}\right)$ and $m / z: 353[(\mathrm{M}-\mathrm{H})-320-\text { acyl }-120-90]^{-}\left(-^{0,2^{\prime \prime \prime}} \mathrm{X}_{0}\right)$, corresponding to the loss of the glucosyl and pentosyl residue $[35,45]$ were also observed. The fragment signals at $\mathrm{m} / z: 383(\mathrm{Ag}+113)$ and $m / z: 353(\mathrm{Ag}+83)$ typical of the di $C$-glycosylflavone were also observed. The relative intensity of the $[(\mathrm{M}-\mathrm{H})-320-(\mathrm{acyl}-18)-120-90]^{-}$signal was higher than that of $[(\mathrm{M}-\mathrm{H})-320-$ $($ acyl -18$)-120]^{-}$in agreement with a 6-C-pentosyl-8-C-glucosyl- substitution. These results suggested that compound 28 was luteolin 7-O-(6"-quinoyl)-rhamnosyl-6- $C$-pentosyl-8- $C, O$-(6"'-acetyl)-glucoside.

Compound 29 presents a molecular ion at $m / z: 547[\mathrm{M}-\mathrm{H}]^{-}$. The MS data showed fragment ion signals at $m / z: 457[(\mathrm{M}-\mathrm{H})-90]^{-}\left(-^{0,3 "} \mathrm{X}_{0}\right), m / z: 353[(\mathrm{M}-\mathrm{H})-90-104]^{-}$and $m / z: 327[(\mathrm{M}-\mathrm{H})-$ 
$116-104]^{-}(\mathrm{Ag}+41), m / z: 297[(\mathrm{M}-\mathrm{H})-146-104]^{-}$and $m / z: 283[(\mathrm{M}-\mathrm{H})-164-86-14]^{-}$. The neutral loss $\left(-^{0,3 "} \mathrm{X}_{0}\right)$ and 104 amu was concluded to correspond to the loss of the $O$-(malonyl)- $C$ glucosyl by interglycosidic $1 \rightarrow 2$ linkage, due to a high relative intensity of the ion $m / z: 353$. Moreover, the fragment ion signal observed at $m / z: 327(\mathrm{Ag}+41)$, is typical of mono $C$-glycosylflavones and confirmed the substitution in the $C-8$ position due to the low relative intensity of the fragment ion $m / z$ : 327 [26]. These results suggested that compound 29 could be luteolin 8-C-(2"-malonyl)-glucoside.

Compound 30 presents a molecular ion at $m / z$ : $935[\mathrm{M}-\mathrm{H}]^{-}$. The MS data also showed a fragment signal at $m / z$ : $651[(\mathrm{M}-\mathrm{H})-(\text { acyl }-18-2 \mathrm{H})-132]^{-}\left(\mathrm{Y}_{0}{ }^{7}\right)$ corresponding to the loss of the an $O$-(acyl)-pentosyl with a $1 \rightarrow 2$ interglycosidic linkage due to its very high relative intensity (81\%). Other fragment signals were observed at $m / z$ : $547[(\mathrm{M}-\mathrm{H})-284-104]^{-}\left({ }^{1, ' "} \mathrm{X}_{0}\right), m / z$ :

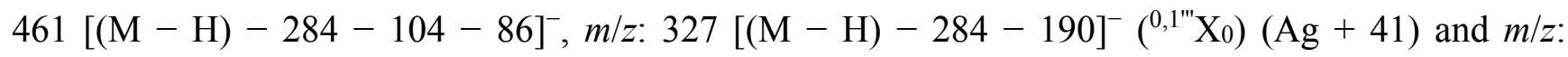
$285[\mathrm{Ag}-\mathrm{H}]^{-}$corresponding to the loss of the $O$-(malonyl)-pentosyl-rhamnosyl- unit with $1 \rightarrow 2$ and $1 \rightarrow 6$ interglycosidic linkages due to the presence the fragment signal $m / z: 285$ (aglycone) [31]. On the basis of these results compound $\mathbf{3 0}$ was concluded to be luteolin 7-O-(2"-dihydrogalloyl)-pentosyl-4'$O-(2 " ', 6 " '-$ malonyl-pentosyl)-rhamnoside.

Compound 32 presents a molecular ion at $m / z$ : $1133[\mathrm{M}-\mathrm{H}]^{-}$. Other fragment signals were observed at $m / z: 1063[(\mathrm{M}-\mathrm{H})-70]^{-}$(base peak), $m / z$ : $917[(\mathrm{M}-\mathrm{H})-70-146]^{-}\left(\mathrm{Y}^{7} 6^{\prime \prime \prime}\right), m / z: 577$ $[(\mathrm{M}-\mathrm{H})-86-146-324]^{-}\left(-\mathrm{Y}^{7} 2^{m} \mathrm{Y}^{7}{ }_{0}\right)$ corresponding to the loss an $O$-(malonyl)-rhamnosyl-diglucosyl with $1 \rightarrow 2$ and $1 \rightarrow 6$ interglycosidic linkages according to relative intensity of the fragments ions. Additional fragment signals were observed at $m / z: 413[(\mathrm{M}-\mathrm{H})-556-164]^{-}\left(-\mathrm{Z}^{3} 6^{\prime \prime \prime \prime}\right)$ and $m / z: 293$ $[(\mathrm{M}-\mathrm{H})-556-164-120]^{-}\left(-^{1,5^{\prime \prime \prime \prime}} \mathrm{X}_{0}^{3}\right)$, suggesting another loss of the $O$-dirhamnosyl moiety. The relative intensity of the ion signal at $\mathrm{m} / \mathrm{z}: 293$ was higher than that of $\mathrm{m} / \mathrm{z}: 413$ indicating a 3-O-dirhamnosyl-aglycone. These results suggested this compound could be kaempferol 7-O-(2"',6"',2"-malonyl)-rhamonsyl-diglucosyl-3-O-(6"'"'-rhamnosyl)-rhamnoside.

\subsection{Hydroxycinnamic Acids}

Eight hydroxycinnamic acid derivatives with low concentrations were detected in the studied fenugreek seeds sample. The tentative characterization of these compounds was based on UV spectra, mass spectral data and comparision with the literature data [52,53]. Different derivatives of hydroxycinnamic acids (caffeic acid, dihydrogallic acid, sinapic acid, gallic acid, coumaric acid) were thus detected in the studied sample with a predominance of caffeic acid derivatives.

Compound 1 presents a molecular ion at $m / z: 827[\mathrm{M}-\mathrm{H}]^{-}$(Table 3). The MS data showed fragment signals at $m / z: 665[(\mathrm{M}-\mathrm{H})-162]^{-}, m / z: 503[(\mathrm{M}-\mathrm{H})-324], m / z: 383[(\mathrm{M}-\mathrm{H})-324-120]^{-}$, $m / z: 341[(\mathrm{M}-\mathrm{H})-324-162]^{-}, m / z: 281[(\mathrm{M}-\mathrm{H})-324-162-60]^{-}, m / z: 221[(\mathrm{M}-\mathrm{H})-324-$ $162-120]^{-}$, and $m / z: 179[(\mathrm{M}-\mathrm{H})-324-162-162]^{-}$. The loss of $324 \mathrm{amu}$ is in agreement with the presence of a diglucoside moiety [54]. The last fragment corresponded to the loss of a caffeic acid moiety. These results indicated that this compound could be tricaffeoyl-glucosyl-glucoside.

Compound 2 presents a molecular ion at $m / z: 695[\mathrm{M}-\mathrm{H}]^{-}$. The MS data showed fragment signals at $m / z: 619[(\mathrm{M}-\mathrm{H})-76]^{-}$, with a high relative intensity $(90 \%), m / z: 407[(\mathrm{M}-\mathrm{H})-76-212]$, with a low relative intensity $(6 \%), m / z: 309[(\mathrm{M}-\mathrm{H})-386]^{-}$(base peak) and $m / z: 180[(\mathrm{M}-\mathrm{H})-515]^{-}$ with a relative intensity of $66 \%$. The last fragment signal indicated the loss of the caffeic acid molecule 
while the $515 \mathrm{amu}$ indicated the loss of the deshydrated dicaffeoyl-hydroxyferulic acid. Therefore, this compound was tentatively identified as tricaffeoyl-hydroxyferulic acid.

Compound 4 presents a molecular ion at $m / z: 947[\mathrm{M}-\mathrm{H}]^{-}$. The MS data showed fragment signals at $m / z: 765[(\mathrm{M}-\mathrm{H})-182]^{-}$(loss of hydrocaffeic acid), $m / z: 382[(\mathrm{M}-\mathrm{H})-182-383]^{-}$(loss of dehydrated hydro feruloyl-sinapic acid), $m / z$ : $205[(\mathrm{M}-\mathrm{H})-182-383-177]^{-}$(loss of sinapic acid). These results, suggested that this compound could be disynapoyl-hydro feruloyl-feruloyl-hydrocaffeic acid.

Compound 5 presents a molecular ion at $m / z$ : $447[\mathrm{M}-\mathrm{H}]$. Other signals were observed at $m / z$ : $224[(\mathrm{M}-\mathrm{H})-223]^{-}, m / z: 152[(\mathrm{M}-\mathrm{H})-295]^{-}$. The loss of the $295 \mathrm{amu}$ is in agreement with a coumaroyl-pentosyl-unit. The last fragment ions corresponded to the loss of the dehydrated gallic acid unit, suggesting that this compound could be galloyl-coumaric acid pentoside.

Compound 6 presents a molecular ion at $\mathrm{m} / \mathrm{z} 499[\mathrm{M}-\mathrm{H}]^{-}$. The MS data showed fragment signals at $\left.m / z: 377[(\mathrm{M}-\mathrm{H})-122]^{-}, m / z: 273(\mathrm{M}-\mathrm{H})-226\right]^{-}, m / z: 163[(\mathrm{M}-\mathrm{H})-336]^{-}$and $m / z$ : $119[(\mathrm{M}-\mathrm{H})-336-44]^{-}$. The loss of the $336 \mathrm{amu}$, indicated to the loss of a dehydrated caffeoyl-quinic acid unit and the last fragment ion observed at $\mathrm{m} / \mathrm{z}: 163$, corresponded to the loss of a coumaroyl radical, suggesting that this compound could be a caffeoyl-coumaroyl-quinic acid.

Compound 7 presents a molecular ion at $m / z: 801[\mathrm{M}-\mathrm{H}]^{-}$. The MS data also showed fragment signals at $m / z: 671[(\mathrm{M}-\mathrm{H})-130]^{-}, m / z: 477[(\mathrm{M}-\mathrm{H})-324]^{-}$corresponding to the loss of diglucosyl. Other signals were observed at $m / z: 323[(\mathrm{M}-\mathrm{H})-324-154]^{-}$(loss of protocatechuic acid), $m / z: 144[(\mathrm{M}-\mathrm{H})-324-154-179]^{-}$(loss of caffeic acid radical). These results suggested that this compound could be dicaffeoyl-protocatechuic acid diglucoside.

\subsection{Quantitation of Flavonoids Glycoside in Crude Fenugreek Seeds}

After having studied the qualitative phytochemical composition of the crude fenugreek seeds extract, the quantitative analysis of the individual identified phenolic compounds was explored and the obtained results are gathered in Table 4. The quantitation of the detected compounds have been made on the basis of the area \% calculation procedure which reports the area of each peak in the chromatogram as a percentage of the total area of all peaks. This method supposes that all components respond equally in the detector and are all eluted from the column. Even if these criteria are may be not assured, the used method provides at least a suitable approximation of the relative amounts of the detected compounds.

The obtained results showed that the identified compounds are present at different percentages, with compound 16, an acylated triglycoside derivative of luteolin, as a major compound (15.80\%). This was followed by compounds 14 (14.41\%) and 20 (12.02\%), which are glycosides of apigenin. The non-acylated apigenin (17 and 11) and kaempferol (31) derivatives were present with similar percentages $(8.82 \%, 9.61 \%$ and $8.71 \%$ respectively). The acylated apigenin glycosides (18) and luteolin (13) compounds were present with $6.59 \%$ and $5.60 \%$ respectively. Finally compounds 15 and 32, which are acylated derivatives of luteolin and kaempferol were present at $3.76 \%$ and $2.52 \%$ respectively. These flavonoids represent the major compounds with $87.80 \%$ of the total identified compounds. The other compounds were present at lower relative percentages. 
Table 3. Chromatographic, spectral data and identification of phenolic acids in fenugreek crude seeds.

\begin{tabular}{cccccc}
\hline Peak & $\boldsymbol{R}_{\mathbf{t}}(\mathbf{m i n})$ & $\boldsymbol{\lambda}_{\max }(\mathbf{n m})$ & {$[\mathbf{M}-\mathbf{H}]^{-}$} & Fragment Signals $(\boldsymbol{m} / \mathbf{z})$ & Compound Identification \\
\hline 1 & 9.23 & 228,264 & 827 & $665,545,383,341,281,221,179,146,129,110$ & tricaffeoyl-glucosyl-glucoside \\
2 & 13.09 & 232,276 & 695 & $619,407,363,309,180,167,128$ & tricaffeoyl-hydroxyferulic acid \\
3 & 17.65 & 248 & 888 & $863,452,431,171,137$ & dihydrogallic acid derivative \\
4 & 19.22 & 228,260 & 947 & $765,483,382,266,205,167,115$ & disynapoyl-hydro feruloyl-feruloyl-hydrocaffeic acid \\
5 & 20.28 & $236,278,328$ & 447 & $224,152,136,108$ & galloyl-coumaric acid pentoside \\
6 & 21.40 & 230,296 & 499 & $377,273,163,119$ & caffeoyl-coumaroyl-quinic acid \\
7 & 23.38 & $240,334,346$ & 801 & $671,477,399,323,261,144,119$ & dicaffeoyl-protocatechuic acid diglucoside \\
8 & 26.46 & $220,234,316$ & 837 & $647,625,587,452,395,347,317,293,165,132,128,115$ & unidentified \\
\hline
\end{tabular}

Table 4. Quantitative chemical composition of the fenugreek crude seeds (results are given in \%).

\begin{tabular}{cccccc}
\hline $\begin{array}{c}\text { Peak } \\
\text { Number }\end{array}$ & $\begin{array}{c}\text { Quantitative Chemical } \\
\text { Composition (\%) }\end{array}$ & $\begin{array}{c}\text { Peak } \\
\text { Number }\end{array}$ & $\begin{array}{c}\text { Quantitative Chemical } \\
\text { Composition (\%) }\end{array}$ & $\begin{array}{c}\text { Peak } \\
\text { Number }\end{array}$ & $\begin{array}{c}\text { Quantitative Chemical } \\
\text { Composition (\%) }\end{array}$ \\
\hline 1 & 0.11 & 12 & 0.66 & 23 & 0.26 \\
2 & 0.15 & 13 & 5.60 & 24 & 0.80 \\
3 & 3.10 & 14 & 14.41 & 25 & 0.08 \\
4 & 0.45 & 15 & 3.76 & 26 & 0.05 \\
5 & 0.43 & 16 & 15.80 & 27 & 0.38 \\
6 & 0.27 & 17 & 8.82 & 28 & 0.45 \\
7 & 0.34 & 18 & 6.59 & 29 & 0.44 \\
8 & 0.70 & 19 & 1.18 & 30 & 0.62 \\
9 & 0.27 & 20 & 12.02 & 31 & 8.71 \\
10 & 0.82 & 21 & 0.31 & 32 & 2.51 \\
11 & 9.61 & 22 & 0.31 & & \\
\hline
\end{tabular}


The quantitative composition of the studied crude seeds was dominated by non-acylated flavonoid glycosides $(48.60 \%)$, followed by acylated flavonoid glycosides $(45.86 \%)$ and finally phenolic acids (5.55\%). Apigenin was the major constitutive aglycon $(61.30 \%)$, followed by luteolin $(21.15 \%)$ and kaempferol $(11.22 \%)$. This showed that the studied sample was dominated by flavone derivatives $(83.20 \%)$.

The data obtained thus demonstrates that acylated and non-acylated flavone derivatives, with apigenin as the main aglycon, dominate the phenolic composition of crude fenugreek seeds.

\section{Materials and Methods}

\subsection{General}

All the chemicals used were of analytical grade and were obtained from Sharlab S.L. (Barcelona, Spain). Apigenin, luteolin, kaempferol, apigenin 8-C-neohesperidoside, luteolin 7-O-glucoside, kaempferol 7-O-neohesperidoside and apigenin 7-O-neohesperidoside were obtained from Extrasynthese (Genay Cedex, France).

\subsection{Plant Materials}

Crude Trigonella foenum-graecum seeds were collected in June 2009 from the north Morocco area. Dried seed samples were ground to a powder using a commercial coffee grinder (Taurus, Barcelona, Spain) and stored in plastic bags and kept in the dark at room temperature until extraction.

\subsection{Accelerated Solvent Extractor (ASE)}

Extraction was carried out using a Dionex ASE 200 Accelerated Solvent Extractor. This technique is also known as pressurized liquid extraction or pressurized fluid extraction. The system, automated and capable of sequential extractions, was made up of stainless steel extraction cells and its programmed parameters (temperature and pressure) were kept at their specified values by electronically controlled heaters and pumps. In this work, the extraction conditions were based on US EPA method [55]. The used solvents were hexane for defatting and a mixture of methanol/water $(50 / 50, v / v)$ for polyphenols extraction. The temperature was $80{ }^{\circ} \mathrm{C}$ and the pressure was $1500 \mathrm{psi}(10.3 \mathrm{Mpa})$ with $5 \mathrm{~min}$ for heating, $8 \mathrm{~min}$ as static time and 3 cycles for extraction. In the end, the extraction cell was flushed with solvent (60\% cell volume) and purged with nitrogen (120 s). Three replicate extractions for each experimental condition were performed $(n=3)$. The extraction procedure was as follows: (1) Sample is loaded in the cell, (2) Cell is filled with solvent up to a pressure of 10.34 MPa, (3) Initial heat-up time is applied, (4) A static extraction with all system valves closed is performed, (5) The cell is rinsed (with 60\% cell volume using extraction solvent), (6) Solvent is purged from the cell with $\mathrm{N}_{2}$ gas and (7) Depressurization takes place.

At the end, the extracts were dried under a nitrogen flow at $40{ }^{\circ} \mathrm{C}$, using Turbovap LV Concentration Evaporator (Caliper, Lifescience, Hopkinton, MA, USA). The residue was redissolved in $2 \mathrm{~mL}$ of methanol/water $(50 / 50, v / v)$ mixture and filtered through a $0.45 \mu \mathrm{m}$ PVDF syringe filter, and analyzed by HPLC. 


\subsection{HPLC-DAD-ESI/MS Analyses}

The HPLC-DAD-ESI/MS apparatus used consisted of a Waters 717 plus autosampler HPLC coupled to a Diode array detector and mass spectrometer (Waters 600 controllers, Hewlett-Packard series 1100 MSD, Agilent Technologies, Aldbronn, Germany). The separation was performed on a reversed-phase Waters Nova-Pak $\mathrm{C}_{18}(4.9 \times 250 \mathrm{~mm}, 4 \mu \mathrm{m}$ particle size) column (Water Milford, MA, USA) at room temperature. The mobile phase consisted of water/AcOH (98/2) (solvent A) and acetronitrile/AcOH (98/2) (solvent B). Separation was performed using the following elution gradient: 0 to $80 \%$ B linear during $55 \mathrm{~min}$, from $80 \%$ to $90 \%$ B during $2 \mathrm{~min}, 90 \%$ B isocratic during $13 \mathrm{~min}$, from $90 \%$ to $95 \%$ B during $10 \mathrm{~min}$ and from $95 \%$ to $100 \% \mathrm{~B}$ during $10 \mathrm{~min}$. This was followed by a washing with methanol and reequilibration of the column from 90 to $120 \mathrm{~min}$. The flow rate was $1 \mathrm{~mL} / \mathrm{min}$, and the injection volume was $10 \mu \mathrm{L}$. The analysis was performed at 280, 310, 330 and $360 \mathrm{~nm}$. Mass spectra were acquired using electrospray ionization in the negative ion mode scanning from $m / z$ : 100 to 3000 using the following fragmentation program: from $m / z: 0$ to $200(100 \mathrm{~V})$ and from $m / z$ : 200 to $3000(200 \mathrm{~V})$. Ionization parameters were as follows: drying gas $\left(\mathrm{N}_{2}\right)$ at a flow of $10 \mathrm{~L} / \mathrm{min}$ and a temperature of $350{ }^{\circ} \mathrm{C}$. The nebulizer pressure was 55 psi and the capillary voltage was $4000 \mathrm{~V}$.

\section{Conclusions}

In this study, HPLC coupled to both ESI/MS and DAD was used to separate and identify 24 flavonoid glycosides in the extract of fenugreek crude seeds. Some minor phenolic acids were also detected and characterized. Both acylated and non-acylated flavonoid derivatives were detected. Most of the identified flavones were apigenin adducts followed by luteolin derivatives, while only two kaempferol glycosides were detected as flavonols. This work presents thus a more complete description of the phenolic compounds present in the crude fenugreek seeds. The obtained results indicate that crude fenugreek seeds could be considered as a rich source of bioactive phenolic compounds. Due to the widely reported antioxidant activity of flavonoids, crude fenugreek seeds could be exploited as an important supplement in food manufacturing such as functional foods or other herbal preparations.

\section{Author Contributions}

Zakia Benayad and Carmen Gómez-Cordovés conceived and designed the experiments; Zakia Benayad performed the experiments; Zakia Benayad and Nour Eddine Es-Safi analyzed and interpreted the data; Zakia Benayad, Carmen Gómez-Cordovés and Nour Eddine Es-Safi drafted and participated to the critical revision of the paper. All authors read the manuscript before submission and approved its publication.

\section{Conflicts of Interest}

The authors declare no conflict of interest. 


\section{References}

1. Basch, E.; Ulbricht, C.; Kuo, G.; Szapary, P.; Smith, M. Therapeutic applications of fenugreek. Altern. Med. Rev. 2003, 8, 20-27.

2. Djeridane, A.; Yousfi, M.; Nadjemi, B.; Boutassouna, D.; Stocker, P.; Vidal, N. Antioxidant activity of some algerian medicinal plants extracts containing phenolic compounds. Food Chem. 2006, 97, 654-660.

3. Sharma, R.D.; Raghuram, T.C.; Rao, N.S. Effect of fenugreek seeds on blood glucose and serum lipids in type I diabetes. Eur. J. Clin. Nutr. 1990, 44, 301-306.

4. Zia, T.; Nazrul Hasnain, S.; Hasan, S.K. Evaluation of the oral hypoglycaemic effect of Trigonella foenum-graecum L in normal mice. J. Ethnopharmacol. 2001, 75, 191-195.

5. Stark, A.; Madar, Z. The effect of an ethanol extract derived from fenugreek (Trigonella foenum-graecum) on bile acid absorption and cholecterol levels in rats. Br. J. Nutr. 1993, 69, 277-287.

6. Srinivasan, K. Fenugreek (Trigonella foenum-graecum): A review of health beneficial physiological effects. Food Rev. Int. 2006, 22, 203-224.

7. Sujapandian, R.; Anuradha, V.V.; Viswanathan, P. Gastroprotective effect of fenugreek seeds (Trigonella foenum-graecum) on experimental gastric ulcer in rats. J. Ethnopharmacl. 2002, 81, 393-397.

8. Amin, A.; Alkaabi, A.; Al-Falasi, S.; Daoud, S.A. Chemopreventive activities of Trigonella foenum-graecum (fenugreek) against breast cancer. Cell Biol. Int. 2005, 29, 687-694.

9. Hettiarachchy, N.S.; Glenn, K.C.; Gnanasambandam, R.; Johnson, M.G. Natural antioxidant extract from fenugreek (Trigonella foenum graecum) for ground beef patties. J. Food Sci. 1996, $61,516-519$.

10. Kavirasan, S.; Naik, G.H.; Gangabhagirathi, R.; Anuradha, C.V.; Priyadarsini, K.I. In vitro studies on antiradical and antioxidant activities of fenugreek (Trigonella foenum-graecum) seeds. Food Chem. 2007, 103, 31-37.

11. Ahmadiani, A.; Javan, M.; Semnanian, S.; Bharat, E.; Kamalinejad, M. Anti-inflammatory and antipyretic effects of Trigonella foenum-graecum leaves extract in the rat. J. Ethnopharmacol. 2001, 75, 283-286.

12. Petit, P.; Sauvaire, Y.; Ponsin, G.; Manteghetti, M.; Fave, A.; Ribes, G. Effect of a fenugreek seed extraction on feeding behaviour in the rat: Metabolic-endocrine correlates. Pharmacol. Biochem. Behav. 1993, 45, 369-374.

13. Petropoulos, G.A. Fenugreek-The Genus Trigonella; Taylor and Francis: London, UK; New York, NY, USA, 2002; pp. 1-255.

14. Wagner, H.; Iyengar, M.A.; Horhammer, L. Vicenin-1 and-2 in the seeds of Trigonella foenum graecum. Phytochemistry 1973, 12, 2548.

15. Huang, W.Z.; Liang, X. Determination of two flavone glycosides in the seeds of Trigonella foenum-graecum L. from various production localities. J. Plant Res. Environ. 2000, 9, 53-54.

16. Rayyan, S.; Fossen, T.; Andersen, U.M. Flavone $C$-glycosides from seeds of fenugreek, Trigonella foenum-graecum L. J. Agric. Food Chem. 2010, 58, 7211-7217. 
17. Liu, Y.; Kakani, R.; Nair, M.G. Compounds in functional food fenugreek spice exhibit anti-inflammatory and antioxidant activities. Food Chem. 2012, 131, 1187-1192.

18. Kenny, O.; Smyth, T.J.; Hewage, C.M.; Brunton, N.P. Antioxidant properties and quantitative UPLC-MS analysis of phenolic compounds from extracts of fenugreek (Trigonella foenum-graecum) seeds and bitter melon (Momordica charantia) fruit. Food Chem. 2013, 141, 4295-4302.

19. Shang, M.; Cais Han, J.; Li, J.; Zhao, Y.; Zheng, J.; Namba, T.; Kadota, S.; Tezuka, Y.; Fan, W. Studies on flavonoids from fenugreek (Trigonella foenum graecum L). Zhongguo Zhong Yao Za Zhi 1998, 23, 614-639 (In Chinese).

20. Fazli, F.R.Y.; Hardman, R. The spice fenugreek (Trigonella foenum-graecum L.): Its commercial varieties of seed as a source of diosgenin. Trop. Sci. 1968, 10, 66-78.

21. Sauvaire, Y.; Ribes, G.; Baccou, J.C.; Loubatieerres-Mariani, M.M. Implications of steroidal sapogenins in the hypocholesterolemic effect of fenugreek. Lipids 1991, 26, 191-197.

22. Taylor, W.G.; Zaman, M.S.; Mir, Z.; Mir, P.S.; Achary, S.N.; Mears, G.J.; Elder, J.L. Analysis of steroidal sapogenins from amber fenugreek (Trigonella foenum-graecum) by capillary gas chromatography and combined gas chromatography/mass spectrometry. J. Agric. Food Chem. 1997, 45, 753-759.

23. Rajalakshmi, R.; Nanavaty, K.; Gumashta, A. Effect of cooking procedures on the free and total niacin content of certain food. J. Nutr. Diet. 1964, 1, 276-280.

24. Bellakhdar, J. La Pharmacopée Marocaine Traditionnelle, Médecine Arabe Ancienne et Savoirs Populaires; Ibis Press: Paris, France, 1997; p. 764. (In French)

25. Truchado, P.; Vit, P.; Ferreres, F.; Tomas-Barberan, F. Liquid chromatography-tandem mass spectrometry analysis allows the simultaneous characterization of $C$-glycosyl and $O$-glycosyl flavonoids in stingless bee honeys. J. Chromatogr. A 2011, 1218, 7601-7607.

26. Guo, X.; Yue, Y.; Tang, F.; Wang, J.; Yao, X.; Sun, J. A comparison of $C$-glycosidic flavonoid isomers by electrospray ionization quadrupole time-of-flight tandem mass spectrometry in negative and positive ion mode. Int. J. Mass Spectrom. 2013, 333, 59-66.

27. Talhi, O.; Silva, A.M.S. Advances in C-glycosylflavonoid research. Curr. Org. Chem. 2012, 16, 859-896.

28. Colombo, R.; Yariwake, J.H.; McCullagh, M. Study of $C$ - and $O$-glycosylflavones in sugarcane extracts using liquid chromatography-Exact mass measurement mass spectrometry. $\mathrm{J}$. $\mathrm{Br}$. Chem. Soc. 2008, 19, 483-490.

29. Bakhtiar, A.; Gleye, J.; Moulis, C.; Fourasté, I. Desorption chemical ionisation mass spectrometry of C-glycosylflavones. Phytochem. Anal. 1994, 5, 86-89.

30. Grayer, R.J.; Kite, G.C.; Abou-Zaid, M.; Archer, L.J. The application of atmospheric pressure chemical ionisation liquid chromatography-mass spectrometry in the chemotaxonomic study of flavonoids: Characterisation of flavonoids from Ocimum gratissimum var. Gratissimum. Phytochem. Anal. 2000, 11, 257-267.

31. March, R.E.; Lewars, E.G.; Stadey, C.G.; Miao, X.S.; Zhao, X.; Metcalfe, C.D. A comparison of flavonoid glycosides by electrospray tandem mass spectrometry. Mass Spectrom. 2006, 248, 61-85.

32. Benayad, Z.; Gómez-Cordovés, C.; Es-Safi, N. Identification and quantification of flavonoid glycosides from fenugreek (Trigonella foenum-graecum) germinated seeds by LC-DAD-ESI/MS analysis. J. Food Comp. Anal. 2014, 35, 21-29. 
33. Domon, B.; Costello, C.E. A systematic nomenclature for carbohydrate fragmentations in FAB-MS/MS spectra of glycoconjugates. Glycoconj. J. 1988, 5, 397-409.

34. Ferreres, F.; Llorach, R.; Gil-Izquierdo, A. Characterization of the interglycosidic linkage in di-, tri-, tetra- and penta-glycosylated flavonoids and differentiation of positional isomers by liquid chromatography/electrospray ionization tandem mass spectrometry. J. Mass Spectrom. 2004, 39, $312-321$.

35. Li, Q.M.; Claeys, M. Characterization and differentiation of diglycosyl flavonoids by positive ion fast atom bombardment and tandem mass spectrometry. Biol. Mass Spectrom. 1994, 23, 406-416.

36. Waridel, P.; Wolfender, J.L.; Ndjoko, K.; Hobby, K.R.; Major, H.J.; Hostettmann, K. Evaluation of quadrupole time-of-flight tandem mass spectrometry and ion-trap multiple-stage mass spectrometry for the differentiation of $C$-glycosidic flavonoid isomers. J. Chromatogr. A 2001, 926, 29-41.

37. Vukics, V.; Kery, A.; Bonn, G.K.; Guttman, A. Major flavonoid components of heartsease (Viola tricolor L.) and their antioxidant activities. Anal. Bioanal. Chem. 2008, 390, 1917-1925.

38. Es-Safi, N.; Kerhoas, L.; Einhorn, J.; Ducrot, P.H. Application of ESI/MS, CID/MS and tandem $\mathrm{MS} / \mathrm{MS}$ to the fragmentation study of eriodictyol 7 -O-glucosyl-( $1 \rightarrow 2)$-glucoside and luteolin 7-O-glucosyl-(1 $\rightarrow 2)$-glucoside. Int. J. Mass Spectrom. 2005, 247, 93-100.

39. Mabry, T.J.; Markham, K.R.; Thomas, M.B. The ultraviolet spectra of flavones and flavonols, isoflavones, dihydroxyflavonols. In The Systematics Identification of Flavonoids; Springer-Verlag: New York, NY, USA, 1970.

40. Cuyckens, F.; Cleays, M. Mass spectrometry in the structural analysis of flavonoids. J. Mass Spectrom. 2004, 39, 1-15.

41. Williams, C.A. Flavone and flavonol O-glycosides. In Flavonoids: Chemistry, Biochemistry and Applications; Anderson, Ø.M., Markham, K.R., Eds.; Taylor \& Francis/CRC: Boca Raton, FL, USA, 2006; pp. 749-856.

42. Becchi, M.; Fraisse, D. Fast atom bombardment and fast atom bombardment collision-activated dissociation/mass-analysed ion kinetic energy analysis of $C$-glycosidic flavonoids. Biomed. Environ. Mass Spectrom. 1989, 18, 122-130.

43. Cuyckens, F.; Rozenberg, R.; de Hoffmann, E.; Claeys, M. Structure characterization of flavonoid $O$-diglycosides by positive and negative nano-electrospray ionization ion trap mass spectrometry. J. Mass Spectrom. 2001, 36, 1203-1210.

44. Ablajan, K.; Abliz, Z.; Shang, X.-Y.; He, J.-M.; Zhang, R.-P.; Shi, J.-G. Structural characterization of flavonol 3,7-di- $O$-glycosides and determination of the glycosylation position by using negative ion electrospray ionization tandem mass spectrometry. J. Mass Spectrom. 2006, 41, 352-360.

45. Ferreres, F.; Gil-Izquierdo, A.; Andrade, P.B.; Valentão, P.; Tomás-Barberán, F.A. Characterization of $C$-glycosyl flavones $O$-glycosylated by liquid chromatography-tandem mass spectrometry. J. Chromatogr. A 2007, 1161, 214-223.

46. Cuyckens, F.; Ma, Y.L.; Pocsfalvi, G.; Cleays, M. Tandem mass spectral strategies for the structural characterisation of flavonoid glycosides. Analusis 2000, 28, 888-895.

47. Ma, Y.L.; Li, Q.M.; van den Heuvel, H.; Claeys, M. Characterization of flavone and flavonol aglycones by collision-induced dissociation tandem mass spectrometry. Rapid Com. Mass Spectrom. 1997, 11, 1357-1364. 
48. Ferreres, F.; Silva, B.M.; Andrate, P.B.; Seabra, R.M.; Ferreira, M.A. Approach to the study of $C$-glycosyl flavones by ion trap HPLC-PAD-ESI/MS/MS: Application to seeds of quince (Cydonia oblonga). Phytochem. Anal. 2003, 14, 352-359.

49. Barreca, D.; Bellocco, E.; Caristi, C.; Leuzzi, U.; Gattuso, G. Distribution of $C$ - and $O$-glycosyl flavonoids, (3-hydroxy-3-methylglutaryl) glycosyl flavanones and furocoumarins in Citrus aurantium L. juice. Food Chem. 2011, 124, 576-582.

50. Ferreres, F.; Gil-Izquierdo, A.; Vinholes, J.; Grosso, C.; Valentão, P.; Andrade, P.B. Approach to the study of $C$-glycosyl flavones acylated with aliphatic and aromatic acids from Spergularia rubra by high-performance liquid chromatography-photodiode array detection/electrospray ionization multi-stage mass spectrometry. Rapid Commun. Mass Spectrom. 2011, 25, 700-712.

51. Ferreres, F.; Andrade, P.B.; Valentão, P.; Gil-Izquierdo, A. Further knowledge on barley (Hordeum vulgare L.) leaves $O$-glycosyl-C-glycosyl flavones by liquid chromatography-UV diode-array detection-electrospray ionization mass spectrometry. J. Chromatogr. A 2008, 1182, $56-64$.

52. Gouveia, S.C.; Castilho, P.C. Characterization of phenolic compounds in Helichrysum melaleucum by high-performance liquid chromatography with on-line ultraviolet and mass spectrometry detection. Rapid Commun. Mass Spectrom. 2010, 24, 1851-1868.

53. Clifford, M.N. The analysis and characterization of chlorogenic foods and other cinnamates. In Methods in Polyphenol Analysis; Santos-Buelga, C.W.G., Ed.; The Royal Society of Chemistry: Cambridge, UK, 2003; pp. 314-333.

54. Romani, A.; Vignolini, P.; Isolani, L.; Ieri, F.; Heimler, D. HPLC-DAD/MS characterization of flavonoids and hydroxycinnamic derivatives in turnip tops (Brassica rapa L. Subsp. sylvestris L.). J. Agric. Food Chem. 2006, 54, 1342-1346.

55. Method 3545A (SW-846): Pressurized Fluid Extraction (PFE) (Revision 1). Available online: http://www.epa.gov/sam/pdfs/EPA-3545a.pdf (accessed on 6 July 2013).

(C) 2014 by the authors; licensee MDPI, Basel, Switzerland. This article is an open access article distributed under the terms and conditions of the Creative Commons Attribution license (http://creativecommons.org/licenses/by/4.0/). 